\title{
Photovoltaic Thermal Collectors with Phase Change Material for Southeast of England
}

Preeti Singh $^{1}$, Rajvikram Madurai Elavarasan ${ }^{2}$, Nallapaneni Manoj Kumar ${ }^{3}$, Sourav Khanna $^{4}$, Victor Becerra ${ }^{4}$, Sanjeev Newar ${ }^{1}$, Vashi Sharma ${ }^{1}$, Jovana Radulovic ${ }^{4}$, Rinat Khusainov $^{4}$ and David Hutchinson ${ }^{4}$

${ }^{1}$ IIT Kanpur, Uttar Pradesh 208016, India

${ }^{2}$ Sri Venkateswara College of Engineering, Tamil Nadu 602117, India

${ }^{3}$ City University of Hong Kong, Kowloon 85PF+87, Hong Kong

${ }^{4}$ University of Portsmouth, Portsmouth PO1 3DJ, UK

sourav.khannal@gmail.com sourav.khanna@port.ac.uk

\begin{abstract}
Temperature elevation of solar photovoltaic (PV) in the exposure of sun should be bound to avoid the fall in efficiency. Phase changing material (PCM) is a proven technology to capture the waste heat of photovoltaic. It provides cooling to $\mathrm{PV}$, increase in efficiency and storage of waste heat. In this paper, the thermal conductivity of PCM heat sink is enhanced by using fins. The dual effect of PCM and fins is explored to increase the efficiency of the photovoltaic collectors. Different types of phase change material arrangements are investigated. Twenty collectors of $200 \mathrm{Wp}$ original PV are compared with the photovoltaic thermal PCM collectors. It is conveyed that, at Southeast England, the collected electricity is boosted by $1.20,1.33,1.40,1.43$ and $1.44 \mathrm{kWh} / \mathrm{day}$ through different types of phase change material arrangements.
\end{abstract}

Keywords: Phase Changing Material, Electricity Yield, Photovoltaic.

\section{$1 \quad$ Introduction}

Solar photovoltaic has shown a great potential for clean electricity generation. However, temperature elevation of PV in the exposure of sun should be bound to avoid the fall in efficiency [1]. Phase Changing Material (PCM) [2] is a proven technology to capture the waste heat of photovoltaic [3-4]. Researchers have examined the following: (i) PV (without cooling mechanism) against PCM cooled PV, (ii) PV against water cooled and PCM cooled PV, (iii) temperature distribution of PCM with respect to elevation angle, (iv) implementation of various methodologies to represent the phase change material, (v) the charging and discharging of the phase changing material, (vi) implementation of the idea of double-channeled PCM and micro channeled sink for the heat retention, (vii) PCM for CPV cooling, (viii) parametric investigation of phase changing material, (ix) best volumes of PCM requirement and the impact of surroundings, (x) capsules for phase change material, (xi) the combined effect of thermoelectric generator and PCM for photovoltaic, (xii) feasibility examination of the phasechanging material, (xiii) the usability of nanomaterial for PCM improve- 
ment, (xiv) the usability of air duct for the PV PCM collector, (xv) various arrangements to bind the rise in PV temperature, (xvi) $\mathrm{PCM}-\mathrm{CuO}$ nano material for binding the PV temperature.

In this paper, the thermal conductivity of PCM heat sink is enhanced by using fins. The dual effect of PCM and fins is explored to increase the efficiency of the photovoltaic collectors at Southeast England.

\section{$2 \quad$ Model}

Rooftop solar photovoltaic phase change material collectors are taken for the analysis and put against rooftop solar photovoltaic collectors (Fig. 1). The elevated angle is taken as $\beta$. The elevation in temperature of the collectors and the electricity yield can be figured out through below model [5-6].

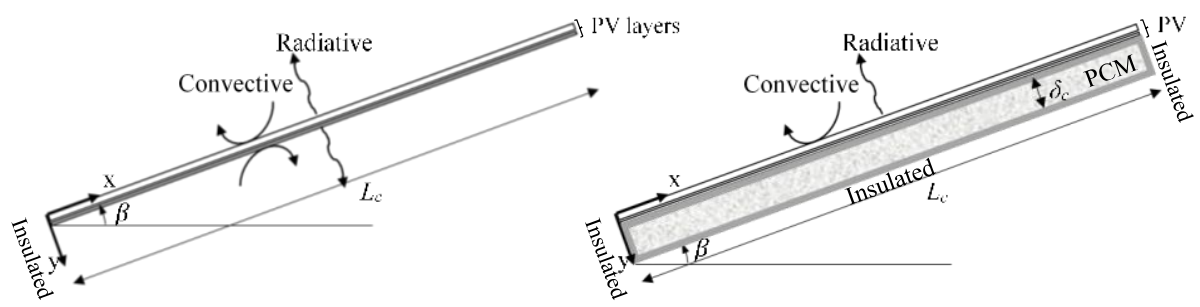

(i) PV

(ii) PV-PCM (No-fin)

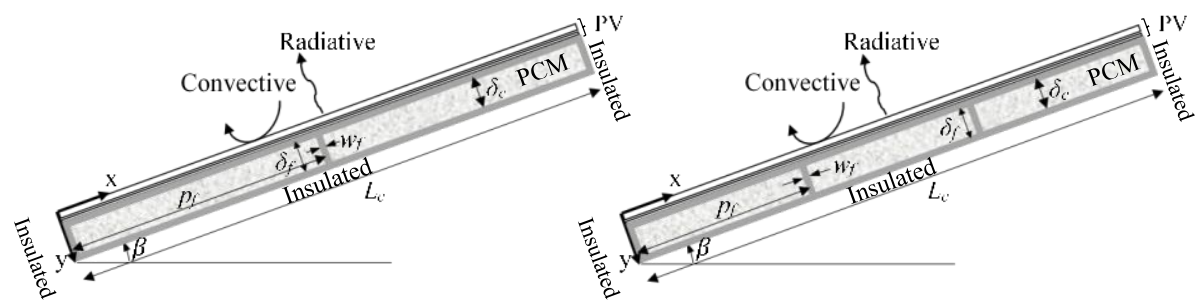

(iii) PV-PCM (One fin)

(iv) PV-PCM (Two fins)

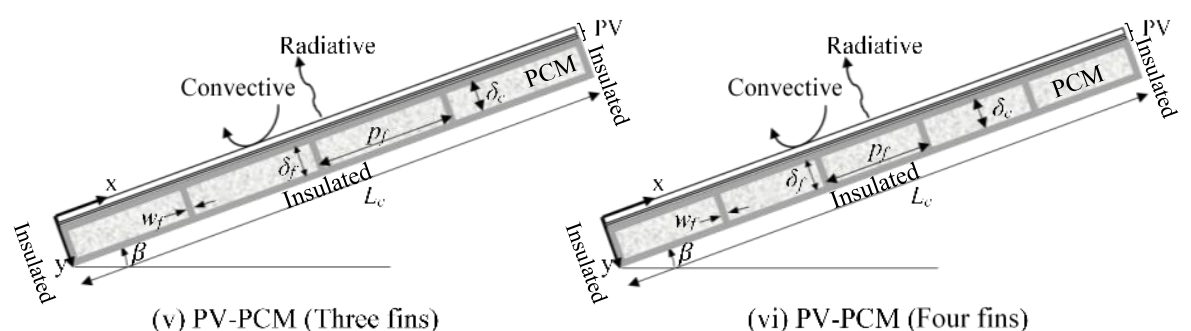

(v) PV-PCM (Three fins)

(vi) PV-PCM (Four fins)

Fig. 1. Solar roof top photovoltaic and photovoltaic phase change material collectors. 
By applying energy conservation, the following equation can be figured out in terms of temperature of system at any point $(T(x, y))$, velocity of PCM $(u)$, thermal diffusivity $(\alpha)$ and heat generation $(G)$

$$
\frac{1}{\alpha}[\dot{T}(x, y)+u . \nabla T]=\nabla^{2} T(x, y)+G
$$

By applying momentum conservation, the following equation can be figured out in terms of density of PCM $(\rho)$, velocity of PCM $(u)$, pressure $(p)$, viscosity $(\mu)$, acceleration due to gravity $(g)$ and expansion coefficient $(\beta)$

$$
\begin{aligned}
& \rho \dot{u}_{x}+\rho(\vec{u} . \nabla) u_{x}=-\frac{\partial p}{\partial x}+\mu \nabla^{2} u_{x}+\rho_{P, l} g_{x}\left[1-\beta_{c}\left\{T_{P}(x, y)-T_{m}\right\}\right] \\
& \rho \dot{u}_{y}+\rho(\vec{u} . \nabla) u_{y}=-\frac{\partial p}{\partial y}+\mu \nabla^{2} u_{y}+\rho_{P, l} g_{y}\left[1-\beta_{c}\left\{T_{P}(x, y)-T_{m}\right\}\right]
\end{aligned}
$$

By applying mass conservation, the following equation can be figured out

$$
\nabla \cdot u=0
$$

The electricity yield $(P)$ can be figured out through below model in terms of inverter efficiency $\left(\eta_{i n v}\right)$, wiring loss efficiency $\left(\eta_{e, l o s s}\right)$, temperature of PV $\left(T_{P V}\right)$, solar insolation $(S)$ and PV area $(A)$.

$$
P=\eta_{\text {inv }} \eta_{e, l o s s} 0.2\left[1-0.005\left(T_{P V}-25\right)+0.085 \ln (\mathrm{S} / 1000)\right] S A
$$

\section{Results}

In the work, twenty collectors of $200 \mathrm{Wp}$ original PV are compared with the photovoltaic thermal PCM collectors at Southeast of England. Paraffin wax 18 is taken to bind the temperature of photovoltaic. A sunny day of summers is considered to carry out the calculations. Solar intensity at photovoltaic and ambient conditions are exhibited (see Fig. 2).

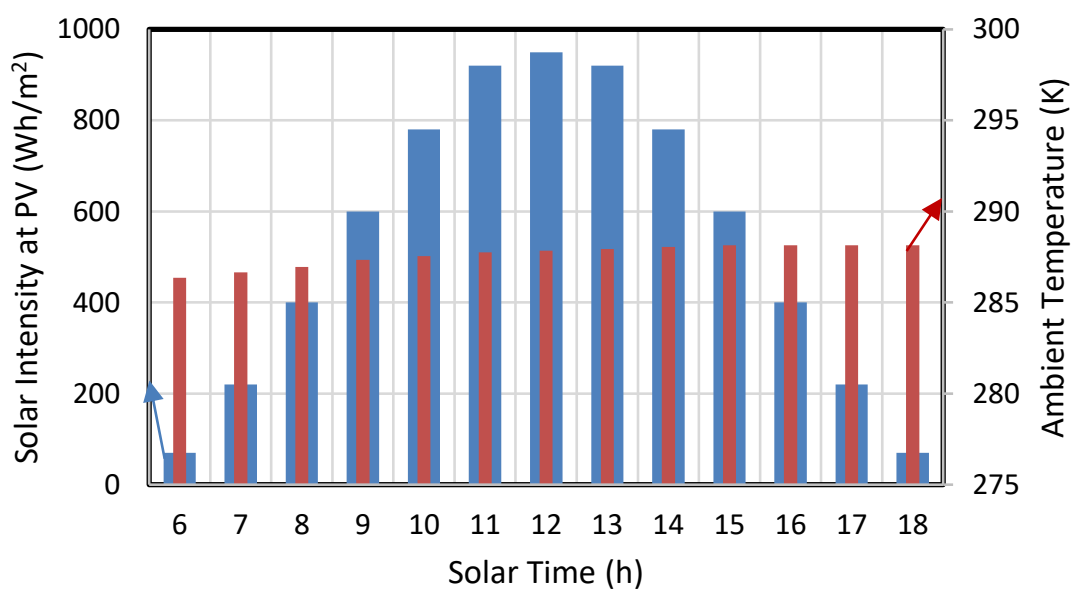

Fig. 2. Solar intensity at photovoltaic collectors and ambient conditions. 
The elevation in photovoltaic temperature for the original PV and photovoltaic phasechanging material collector are exhibited in Fig. 3 and Fig. 4. It can be conveyed that the phasechanging material has bound the elevation in photovoltaic temperature to $304 \mathrm{~K}$.

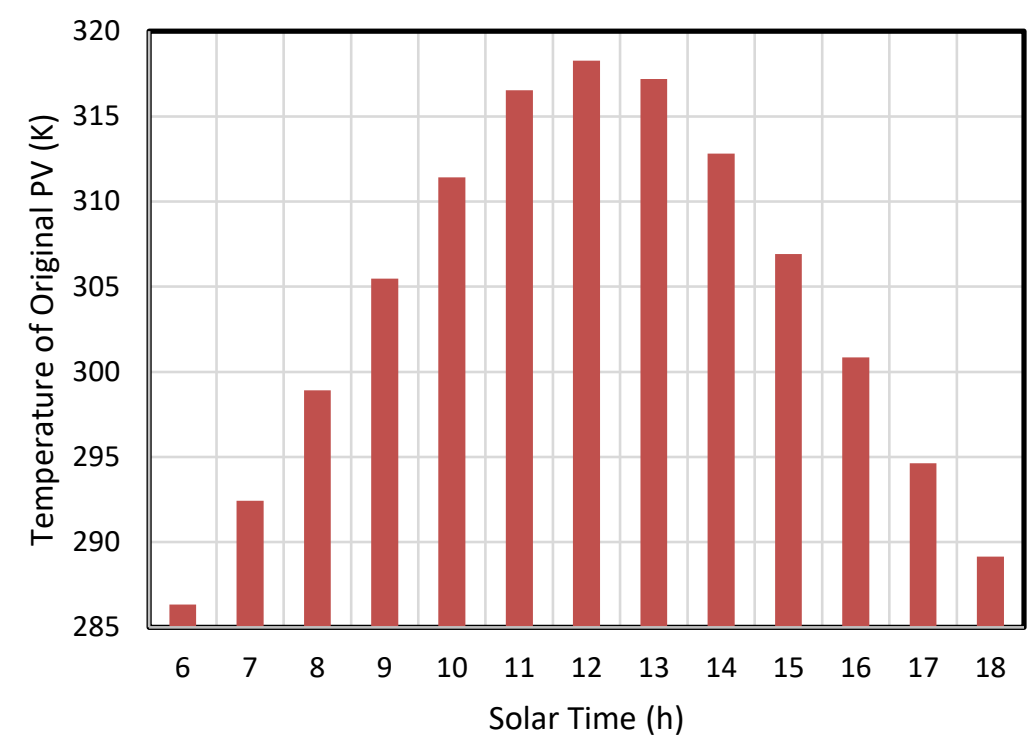

Fig. 3. Elevation in PV temperature.

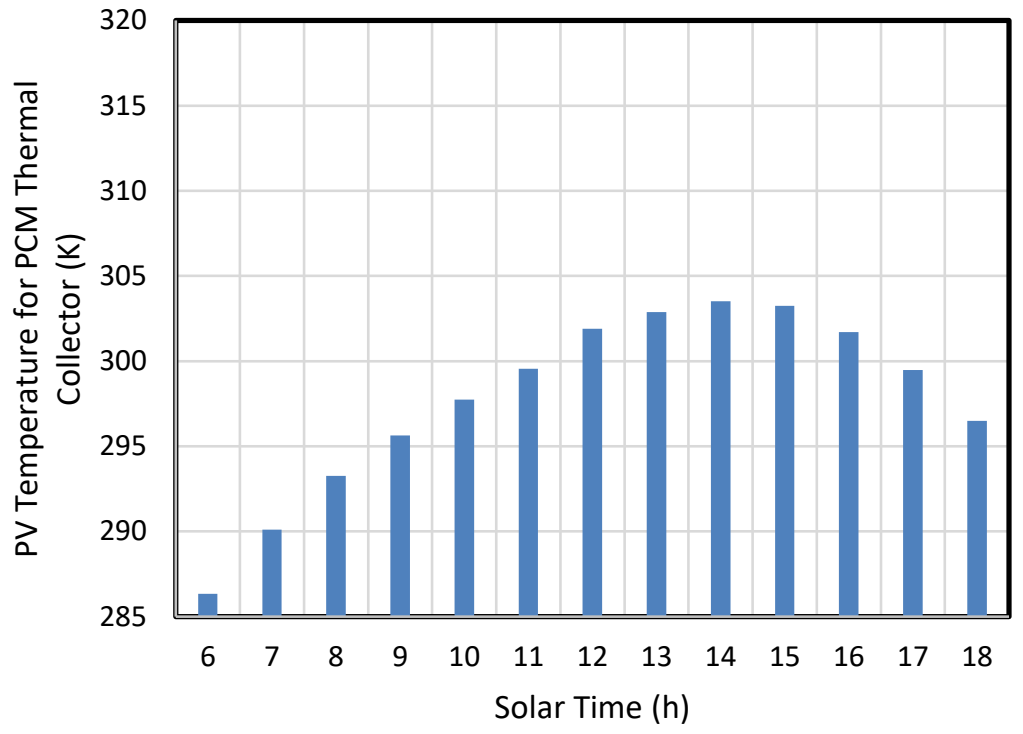

Fig. 4. Elevation in PV temperature. 
Electricity yield from the considered collectors is exhibited in Fig. 5. It can be conveyed that the collected electricity is boosted by $1.20,1.33,1.40,1.43$ and 1.44 $\mathrm{kWh}$ /day through different types of phase change material arrangements having nofin, one fin, two fins, three fins and four fins respectively. The increment in number of fins boosts the contact surface area between PCM and fins resulting in enhanced thermal conductivity of the overall heat sink and, consequently, leads to higher PV cooling and higher electricity generation.

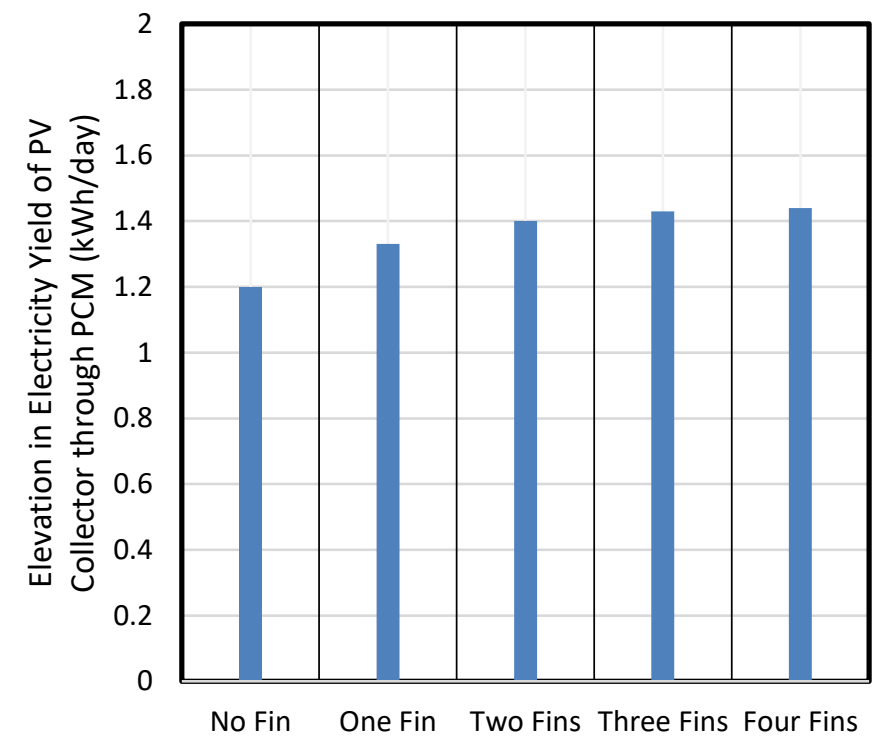

Fig. 5. Elevation in yield of PV collector through PCM.

\section{Conclusions}

In the work, twenty collectors of $200 \mathrm{Wp}$ original PV are compared with the photovoltaic thermal phase change material collectors at Southeast of England. It can be conveyed that

- The phase change material has bound the elevation in photovoltaic temperature to $304 \mathrm{~K}$.

- The collected electricity is boosted by $1.20,1.33,1.40,1.43$ and $1.44 \mathrm{kWh} /$ day through different types of phase change material arrangements having no-fin, one fin, two fins, three fins and four fins respectively.

\section{Acknowledgement}

Financial support from Interreg2Seas project SOLARISE (cont. No 2S04-004) to University of Portsmouth is gratefully acknowledged. 


\section{References}

1. 1. Khanna, S., Singh, P., Newar, S., Sharma, V., Mallick, T.K., Radulovic, J., Khusainov, R., Hutchinson, D., Becerra, V.: Fins integrated phase change material for solar photovoltaic for South East United Kingdom. AIP Conference Proceedings 2149, 060003 (2019).

2. Khanna, S., Reddy, K.S., Mallick, T.K.: Photovoltaic System Integrated with Phase Change Material for South West UK Climate. AIP Conference Proceedings 2012, 080007 (2018).

3. Khanna, S., Reddy, K.S., Mallick, T.K.: Effect of climate on electrical performance of finned phase change material integrated solar photovoltaic. Solar Energy 174, 593-605 (2018).

4. Al Siyabi, I., Khanna, S., Mallick, T., Sundaram, S.: An experimental and numerical study on the effect of inclination angle of phase change materials thermal energy storage system. Journal of Energy Storage 23, 57-68 (2019).

5. Khanna, S., Newar, S., Sharma, V., Reddy, K.S., Mallick, T.K.: Optimization of fins fitted phase change material equipped solar photovoltaic under various working circumstances. Energy Conversion and Management 180, 1185-1195 (2019).

6. Khanna, S., Newar, S., Sharma, V., Reddy, K.S., Mallick, T.K., Radulovic, J., Khusainov, R., Hutchinson, D., Becerra, V.: Electrical enhancement period of solar photovoltaic using phase change material. Journal of Cleaner Production 221, 878-884 (2019). 